14.06

\title{
Исследование влияния материала микрофлюидного чипа на полимеразную цепную реакцию
}

\author{
(C) А.Н. Тупик, Г.Е. Рудницкая, Т.А. Лукашенко, А.А. Евстрапов \\ Институт аналитического приборостроения РАН, \\ 190103 Санкт-Петербург, Россия \\ e-mail: tunix@yandex.ru
}

Поступило в Редакцию 26 декабря 2019 г.

В окончательной редакции 26 декабря 2019 г.

Принято к публикации 17 февраля 2020 г.

Проверено влияние ряда полимерных материалов отечественных и зарубежных производителей на полимеразную цепную реакцию. Установлено, что в микрочипе из полиметилметакрилата не наблюдается адсорбции компонентов реакционной смеси при комнатной температуре, однако при проведении полимеразной цепной реакции в микрочипе происходит снижение эффективности реакции при малых концентрациях ДНК.

Ключевые слова: ПЦР, микрофлюидный чип, микрочип, ингибирование, полимерные материалы.

DOI: $10.21883 / J T F .2020 .09 .49692 .436-19$

\section{Введение}

Микрофлюидные чипы (микрочипы) представляют собой устройства с системой микроразмерных каналов и резервуаров. Работа с малыми объемами позволяет снизить расход реактивов, разместить на одном устройстве большое количество реакционных камер, реализовать новые подходы и методики анализа. Широко востребованы микрочипы для генетического анализа, на основе которых разрабатываются малогабаритные автоматизированные системы, позволяющие реализовать комплексный анализ пробы [1-4].

Полимеразную цепную реакцию (ПЦР) применяют для получения фрагментов ДНК в достаточном количестве с целью детектирования, идентификации и анализа нуклеиновых кислот. Особенностью ПЦР является режим многократного циклического нагрева и охлаждения. Миниатюризация обеспечивает эффективные условия для протекания реакции и сокращает ее продолжительность. Однако высокое соотношение площади поверхности к объему у микроструктур (от $3-10$ до $\sim 150$ по сравнению с 1.4 у пробирок [5]) усиливает влияние рабочей поверхности на результат анализа при контакте материала с биологической пробой и реагентами. Механизм влияния обусловлен как химическим взаимодействием, так и физической адсорбцией компонентов смеси на внутренней поверхности микроструктур. Адсорбция может привести к изменению соотношения компонентов в растворе и, как следствие, к снижению эффективности реакции вплоть до ее прекращения (ингибирования). Поэтому в микрочипах для ПЦР часто используют защитные покрытия (статическая модификация) $[6,7]$ или поверхностно-активные добавки, конкурирующие с компонентами реакции при адсорбции на стенках микрочипа (динамическая модификация) $[8,9]$, а также объединение этих методов (предва- рительная промывка микроструктур раствором бычьего сывороточного альбумина (БСА) и др.) [5,10]. Можно увеличивать концентрацию адсорбирующихся реагентов, чтобы они были свободно доступны в реакционной смеси (например, для кремниевых микрочипов вместо 0.025 units/ $\mu 1$ полимеразы использовать 0.1 units/ $\mu 1$ [8]), однако при адсорбции нуклеиновых кислот теряется возможность анализа малых концентраций ДНК.

Наиболее часто используемые материалы для микрочипов, такие как кремний, кварцевые стекла, поликарбонат (ПК), полиметилметакрилат (ПММА) и другие [11], хорошо изучены, и технологии изготовления микроструктур в них уже отработаны. Благодаря высокой химической стойкости и низкой поверхностной энергии все чаще применяются материалы на основе циклоолефина (COP) и его сополимеров (COC), а также фторсодержащие материалы, например политетрафторэтилен (ПТФЭ, фторопласт-4). Однако при выборе инертных материалов следует учитывать, что низкая адгезия, невосприимчивость к органическим растворителям, щелочам, кислотам приводит к сложностям при изготовлении микроструктур и при соединении деталей микрочипа между собой (герметизация) и с другими элементами (система подвода пробы, пневматические элементы). Для активных элементов микрофлюидики (микроклапаны, микронасосы) применяются эластомеры - упругие резиноподобные материалы, деформируемые без значительных усилий; наибольшее распространение получил полидиметилсилоксан (ПДМС). Также находят применение в микрофлюидике фотоотверждаемые и эпоксидные композиты, свойства которых очень разнообразны, но многие из них обладают высоким светопропусканием, химической и термической устойчивостью. Они, как и ПДМС, позволяют получать относительно недорогие микрофлюидные устройства методом „мягкойс литографии. 
В ИАП РАН были разработаны микрочипы для ПЦР из стеклянных и полимерных материалов, герметизированных фотоотверждаемыми клеевыми композициями [12]. Задачей настоящей работы является исследование влияния применяемых полимерных материалов на ПЦР и определение наиболее подверженных адсорбции компонентов реакционной смеси.

Полимерный микрочип представлял собой неразъемное соединение двух пластин ПММА толщиной $1 \mathrm{~mm}$. В одной из них (канализированной пластине) методом лазерной гравировки (абляции) были созданы углубления - реакционные камеры с подводящими каналами (глубина микроструктур $0.3 \mathrm{~mm}$, соотношение площади поверхности к объему $\sim 8 \mathrm{~mm}^{-1}$ ). Во второй (защитной пластине) методом лазерной резки были сделаны входные/выходные отверстия. Канализированную пластину герметизировали защитной при помощи технологии склеивания. Необходимо отметить, что особенностью клеевого соединения является наличие между пластинами прослойки отвержденного клея, которая в случае микрочипа является частью стенки его реакционной камеры и контактирует с реакционной смесью для ПЦР. Таким образом, компоненты клея (помимо материала пластин) тоже могут влиять на проводимую в микрочипе реакцию. Для склеивания микрочипа использовали фотоотверждаемый клей Permabond UV 630 (Engineering Adhesives, Великобритания). Дополнительное исследование устойчивости отвержденного клея Permabond UV 630 в воде показало, что при нагреве образцов выше $90^{\circ} \mathrm{C}$ их масса уменьшается на $\sim 1 \%$, а жидкость приобретает характерный запах, что, вероятно, связано с переходом в раствор низкомолекулярных компонентов клея [13]. Поэтому одной из задач работы была проверка ингибирования полимеразной цепной реакции подобным раствором, предположительно содержащим низкомолекулярные компоненты клея Permabond UV 630.

\section{1. Способы определения влияния материала микрочипа на ПЦР}

Обнаружение ингибирующих веществ часто затруднено. Присутствие ингибиторов может вызвать снижение эффективности ПЦР, а может выражаться в задержке реакции на начальных этапах. Первое можно определить при детектировании флуоресценции в режиме реального времени по увеличению наклона графика интенсивности свечения красителя от количества циклов ПЦР, второе обусловливает более позднее начало роста флуоресценции (смещение порогового цикла ПЦР). Однако подобные проблемы могут быть вызваны разными причинами, например, неточностью температурного режима.

Еще в 1996 году после обнаружения эффекта ингибирования ПЦР необработанным кремнием [6] был предложен способ выявления влияния материала за счет добавления в пробирки для ПЦР кремниевого порошка (4.6 mg на реакцию) с разными типами модификации поверхности. Положительный результат реакции свидетельствовал об эффективной модификации кремния, что позволило выбрать способ обработки кремниевой поверхности микрочипа для ПЦР. В работе [14] при добавлении в пробирки для ПЦР золотых наночастиц $(5,10$ и $20 \mathrm{~nm})$ было показано, что на ингибирование реакции влияет общая площадь поверхности частиц независимо от их размера, а вероятной причиной называлось связывание с наночастицами фермента (полимераза). Различные полимеразы отличаются разной устойчивостью к ингибиторам. Например, в работе [15] было показано, что полимераза Phusion более чувствительна к присутствию наночастиц оксидов металлов $\left(\mathrm{ZnO}, \mathrm{Fe}_{2} \mathrm{O}_{3}\right.$, $\mathrm{Fe}_{3} \mathrm{O}_{4}$ и $\mathrm{CuO}$ ) по сравнению с полимеразой Ex Taq, при этом наночастицы $\mathrm{CeO}_{2}$ и $\mathrm{TiO}_{2}$ ингибировали реакцию каждой из двух полимераз.

Исследователи в работе [16] проводили ПЦР с растворами, пропущенными через трубки длиной $40 \mathrm{~cm}$ и $3 \mathrm{~m}$ из различных фторполимеров. Было показано, что результат реакции не зависит от скорости потока и времени контакта реагентов с материалом и ухудшается при увеличении соотношения площади поверхности к объему. Исключая из раствора по одному из реагентов, исследователи установили, что на стенках фторполимерных трубок адсорбировались преимущественно флуоресцентный краситель SYBR Green и ДНК. Так же в работе [16] продемонстрировано, что наличие примесей в материале может ухудшать результат ПЦР при отсутствии влияния от химически чистого аналога.

В другой работе [10] с целью определения критического для ПЦР значения соотношения площади поверхности к объему (в диапазоне от 0 до $6 \mathrm{~mm}^{-1}$ ) в пробирки с реакционной смесью добавляли фрагменты нарезанных полимерных капилляров. Исследования проводили с использованием Тор-полимеразы, представляющей собой более устойчивую к ингибиторам модификацию Таqполимеразы. Было продемонстрировано, что снижение эффективности ПЦР у разных материалов (ПК, ПММА, СОС) происходит с разной интенсивностью, при этом предварительная инкубация образцов в растворе БСА $(0.2 \mu \mathrm{g} / \mu \mathrm{l})$ в течение $12 \mathrm{~h}$ значительно улучшает результат ПЦР у всех исследуемых материалов.

В работе [17] изучали адсорбцию реагентов ПЦР при использовании большого списка материалов, применяемых в микрофлюидике. Материалы размером > $>\mathrm{mm}^{3}$ измельчали, переносили в пробирку, добавляли готовый раствор для ПЦР объемом $30 \mu 1$ (с добавлением БСА или без него), перемешивали и инкубировали на льду $30 \mathrm{~min}$, а затем проводили ПЦР. Был сделан вывод, что следующие материалы не ингибируют ПЦР: кварц с покрытием $\mathrm{SiO}_{2}$, натриево-силикатные стекла и стекла пирекс, полипропелен (ПП), политетрафторэтилен (ПТФЭ), отвержденные полимеры - ПДМС и оптический клей NOA68, некоторые виды минеральных масел и парафинов. Добавление БСА позволяло значительно расширить этот список (ПММА, ПК, ПВХ, NOA61 
и др). Для определения причины ингибирования исследуемые материалы добавляли в раствор, в котором отсутствовала ДНК или полимераза, также инкубировали, затем раствор переносили в другую пробирку, добавляли недостающий компонент и проводили ПЦР. Адсорбция полимеразы (SpeedStar) была характерна для ПММА, ПВХ, эпоксидных клеев, металлических трубок и др., при этом для воска и акриловых клеев наблюдалась также и адсорбция ДНК. В работе [7], помимо предварительной оценки ПЦР в пробирках с кусочками модифицированного кремния, для того, чтобы достичь сопоставимого соотношения площади контакта поверхности с раствором, микрочип также заполняли реакционной смесью, инкубировали $5 \mathrm{~min}$ при $25^{\circ} \mathrm{C}$, затем раствор переносили в пробирки и проводили ПЦР.

Таким образом, выделим следующие подходы: 1 проверка материала одновременно с проведением ПЦР (добавление измельченных образцов в пробирки или проведение реакции непосредственно в микрочипе), 2 использование реакционной смеси после контакта с материалом. Преимуществом первого является соблюдение реальных условий ПЦР, однако второй подход предоставляет больше возможностей для выявления особенностей взаимодействия материала с реакционной смесью. Для первого способа можно выделить исследования на традиционном оборудовании (в пробирках, планшетах) либо на специально разработанных устройствах для микрочипов. Применение традиционного оборудования позволяет быстро и просто провести предварительную проверку материалов. Использование специального оборудования для микрочипов подразумевает ряд технологических исследований для оптимизации условий нагрева микроустройства с учетом его конструкции и применяемых материалов.

\section{2. Применяемые материалы и реагенты}

Были исследованы образцы, относящиеся к следующим типам полимеров: термопласты полиметилметакрилат (ПММА), поликарбонат (ПК), полиуретан (ПУ), полиэтилентерефталат (ПЭТ), полиэтилентерефталатгликоль (ПЭТГ), циклоолефин (СОР), оптически прозрачные эпоксидные клеи-компаунды (ПЭО) и фотоотверждаемый клей на акрилатной основе, кремнийорганические (силиконовые) эластомеры (ПДМС и его аналоги). Перечень материалов приведен в табл. 1 и 2. Из всех перечисленных материалов можно изготавливать основные элементы микрочипа с микроструктурами, а клеи и силиконовые компаунды также могут применяться при герметизации многослойного микрочипа. Дополнительно проверяли медицинские трубки с внешним диаметром $4 \mathrm{~mm}$ из поливинилхлорида (ПВХ) желтого и белого цвета, используемые для подачи реагентов.

Трубки, пластины и пленки промывали спиртом и дистиллированной водой, сушили при комнатной тем- пературе. Образцы клея Permabond UV 630 выдерживали 20 min под УФ-лампой (ДРШ-250, Россия). Основу эпоксидных компаундов и кремнийорганических композиций смешивали с катализатором и отверждали при температуре $60-80^{\circ} \mathrm{C}$ согласно инструкции производителя. Подготовленные образцы хранили в закрытой таре не менее недели. Из материалов нарезали фрагменты, массу которых измеряли на электронных лабораторных весах CE224-C („Сартогосм“, Россия). Для исследований выбирали 3-5 фрагментов массой около $3 \mathrm{mg}$.

ПЦР-РВ проводили на оборудовании, разработанном в ИАП РАН, используя набор „ПЦР-Микс“ М-428 („Синтол“, Россия), праймеры и флуоресцентный зонд TaqMan („ДНК-Синтез“, Россия). Итоговый объем реакционной смеси составлял $25 \mu 1$. Конечная концентрация полимеразы SynTaq составляла 0.02 units/ $\mu 1$. Также в состав смеси входили глицерин и Tween 20 (не более $0.05 \%$ каждого). БСА в реакционную смесь не добавляли. В качестве мишени использовали синтезированный фрагмент ДНК длиной 226 нуклеотидов в конечной концентрации $\sim 4 \cdot 10^{3}$ копий на $\mu 1$ и 200 копий на $\mu 1$. Для исследований адсорбции отдельных компонентов реакционной смеси вместо „ПЦР-Микс“ применяли набор реагентов R-412 („Синтол“, Россия), позволяющий самостоятельно готовить реакционную смесь для ПЦР.

\section{3. Экспериментальные исследования}

Проверяемые материалы помещали в пробирки $(0.2 \mathrm{ml})$ и добавляли $25 \mu 1$ готовой смеси для ПЦР. Реакцию проводили на приборе АНК-32 (ИАП РАН). Режим ПЦР - прогрев $5 \mathrm{~min}$ при $95^{\circ} \mathrm{C}$ и 50 циклов по программе: $60^{\circ} \mathrm{C}$ в течение $60 \mathrm{~s}, 95^{\circ} \mathrm{C}$ в течение $20 \mathrm{~s}$. Величину порогового цикла ПЦР $\left(C_{t}\right)$ определяли с применением программного обеспечения прибора по трем-пяти повторам. Увеличение порогового цикла на одну единицу соответствует двукратному уменьшению производительности реакции, поэтому при разнице +1.0 и более между $C_{t}$ в пробирках с образцами материалов и в пробирках без добавок считалось, что материал ингибирует реакцию.

Определение влияния раствора низкомолекулярных компонентов клея Permabond UV 630 на ПЦР проводили следующим образом: в реакционные камеры микрочипа, герметизированного методом склеивания, вводили дистиллированную воду и заклеивали отверстия адгезивными пленками („Современные технологии“, Россия). Затем нагревали микрочип по программе ПЦР. Потом жидкость (которая приобретала характерный запах) извлекали из реакционной камеры и на ее основе готовили ПЦР-смесь, заменяя воду из коммерческого набора „ПЦР-Микс“. По прописи производителя вода занимает $8 \mu 1$ из $25 \mu 1$ ( 30\% объема). ПЦР проводили в пробирках в трех повторах, применяя указанные выше критерии. 
Таблица 1. Результаты проверки пластиков на ингибирование реакции ПЦР-РВ

\begin{tabular}{|c|c|c|c|c|c|c|}
\hline № & Название & Производитель & Форма & Macca, mg & Пороговый цикл & $\begin{array}{c}\text { Разница } \\
\text { с контролем, цикл }\end{array}$ \\
\hline 1 & ПММА ACRYMA 72 & ДОС, Россия & Пластина $1 \mathrm{~mm}$ & $3.1 \pm 0.5$ & $25.0 \pm 0.2(n=5)$ & -0.3 \\
\hline 2 & ПММА ТОСП & ДОС, Россия & Пластина $1 \mathrm{~mm}$ & $2.9 \pm 0.3$ & $25.1 \pm 0.0(n=5)$ & -0.2 \\
\hline 3 & ПММА ТОСН & ДОС, Россия & Пластина $1 \mathrm{~mm}$ & $3.1 \pm 0.2$ & $25.2 \pm 0.2(n=5)$ & -0.1 \\
\hline 4 & ПК Novattro & СафПласт, Россия & Пластина $1 \mathrm{~mm}$ & $3.2 \pm 0.2$ & $25.1 \pm 0.1(n=4)$ & -0.2 \\
\hline 5 & ПУ PR 700 (черный) & Synthene, Франция & Пластина $1 \mathrm{~mm}$ & $3.4 \pm 0.4$ & $25.1 \pm 0.1(n=5)$ & -0.2 \\
\hline 6 & ПЭТ & DuPont, США & Пленка 0.2 mm & $3.1 \pm 0.3$ & $24.8 \pm 0.0(n=4)$ & -0.5 \\
\hline 7 & ПЭТГ & Precision Metals, США & Пленка 0.4 mm & $3.4 \pm 0.5$ & $24.8 \pm 0.2(n=3)$ & -0.5 \\
\hline 8 & COP ZeonorFilm14-188 & Zeon, Германия & Пленка 0.2 mm & $3.1 \pm 0.2$ & $25.5 \pm 0.1(n=3)$ & +0.2 \\
\hline 9 & COP ZeoNex-690R & Zeon, Германия & Гранулы & $34 \pm 0.3$ & $24.6 \pm 0.3(n=3)$ & -0.7 \\
\hline 10 & ПХВ (желтый) & SFM, Германия & Трубка Ø 4 mm & $3.1 \pm 0.2$ & $26.2 \pm 0.8(n=5)$ & +0.9 \\
\hline 11 & ПХВ (белый) & SFM, Германия & Трубка Ø $4 \mathrm{~mm}$ & $3.0 \pm 0.3$ & $26,2 \pm 0.3(n=5)$ & +0.9 \\
\hline
\end{tabular}

Таблица 2. Результаты проверки отвержденных полимерных композиций на ингибирование реакции ПЦР-РВ

\begin{tabular}{l|l|l|l|l|l|l}
\hline № & \multicolumn{1}{|c|}{ Название } & \multicolumn{1}{|c|}{ Производитель } & \multicolumn{1}{|c}{ Полимер } & Масса, mg & Пороговый цикл & $\begin{array}{c}\text { Разница } \\
\text { с контролем, цикл }\end{array}$ \\
\hline 1 & ПЭО-210 & СПбГТИ(ТУ), Россия & Эпоксидный & $3.0 \pm 0.2$ & $25.2 \pm 0.1(n=3)$ & -0.1 \\
\hline 2 & ПЭО-221 & СПбГТИ(ТУ), Россия & Эпоксидный & $2.8 \pm 0.1$ & $25.4 \pm 0.2(n=5)$ & +0.1 \\
\hline 3 & Реrmabond UV630 & $\begin{array}{l}\text { Engineering Adhesives, } \\
\text { Великобритания }\end{array}$ & Акриловый & $3.0 \pm 0.4$ & $25.5 \pm 0.1(n=3)$ & +0.2 \\
\hline 4 & Sylgard-184 & DоwСorning, США & Кремнийорганический & $3.0 \pm 0.4$ & $25.5 \pm 0.1(n=4)$ & +0.2 \\
\hline 5 & Силастик Т4 & Пента Север, Россия & Кремнийорганический & $3.2 \pm 1.0$ & $26.1 \pm 0.5(n=3)$ & +0.8 \\
\hline 6 & Пентэласт-712 & ПЕНТА-91, Россия & Кремнийорганический & $3.0 \pm 0.4$ & $25.5 \pm 0.4(n=3)$ & +0.2 \\
\hline 7 & Пентэласт-750 & ПЕНТА-91, Россия & Кремнийорганический & $3.3 \pm 0.5$ & $25.4 \pm 0.5(n=3)$ & +0.1 \\
\hline 8 & КРЕОЛ & СУРЭЛ, Россия & Кремнийорганический & $2.9 \pm 0.3$ & $25.4 \pm 0.2(n=4)$ & +0.1 \\
\hline 9 & СКТН & ПЕНТА-91, Россия & Кремнийорганический & $3.2 \pm 0.5$ & $25.9 \pm 0.5(n=3)$ & +0.6
\end{tabular}

В микрочипах исследовали адсорбцию ключевых компонентов реакции - полимеразы SynTaq и молекул ДНК-мишени. Во избежание неконтролируемого начала реакции микрочип заполняли ПЦР-смесью без ДНК, герметизировали адгезивными пленками и хранили при $+4^{\circ} \mathrm{C}$ в холодильнике. Смесь с наличием полимеразы выдерживали в микрочипе 2 и $24 \mathrm{~h}$, затем переносили в пробирку, добавляли недостающие компоненты и проводили ПЦР. Для контроля использовали ту же смесь, хранившуюся 2 и $24 \mathrm{~h}$ в полипропиленовых пробирках. Для определения адсорбции ДНК-мишени и остальных компонентов реакции (без ДНК, без полимеразы) исходной раствор фрагментов ДНК или готовую реакционную смесь без добавления ДНК и полимеразы выдерживали в микрочипе в течение $2 \mathrm{~h}$ при комнатной температуре. Затем растворы переносили в пробирки, добавляли недостающие компоненты и проводили ПЦР. Все реакционные камеры микрочипов использовали только один раз.

Для проведения ПЦР в микрочипе реакционную камеру заполняли готовой смесью для ПЦР, отверстия герметизировали адгезивными пленками и помещали микрочип в специально разработанный макет амплификатора (ИАП РАН) с плоской поверхностью термоциклера. Режим ПЦР - прогрев 5 min при $95^{\circ} \mathrm{C}$ и 50 циклов по программе: $60^{\circ} \mathrm{C}$ в течение $80 \mathrm{~s}, 95^{\circ} \mathrm{C}$ в течение $20 \mathrm{~s}$. Величину порогового цикла ПЦР-РВ $\left(C_{t}\right)$ определяли с применением программного обеспечения макета. 


\section{4. Результаты}

Присутствие исследуемых пластиков при проведении ПЦР в пробирках не приводит к увеличению порогового цикла на 1.0 и более (табл. 1 и 2), следовательно, можно сделать вывод, что эти материалы не ингибируют реакцию. Дополнительная проверка пластин ПК, ПММА и ПУ с более низкой концентрацией ДНК-мишени $(\sim 200$ копий на $\mu 1)$ также не выявила факта ингибирования. Замечено, что образцы ПЭТГ и Пентэласт-750 после проведения ПЦР становятся непрозрачными. Кипячение пленок ПЭТГ в течение $20 \mathrm{~min}$ как в щелочной буферной среде $(\sim \mathrm{pH} 8)$, имитирующей смесь для ПЦР, так и в дистиллированной воде вызывало помутнение образцов,

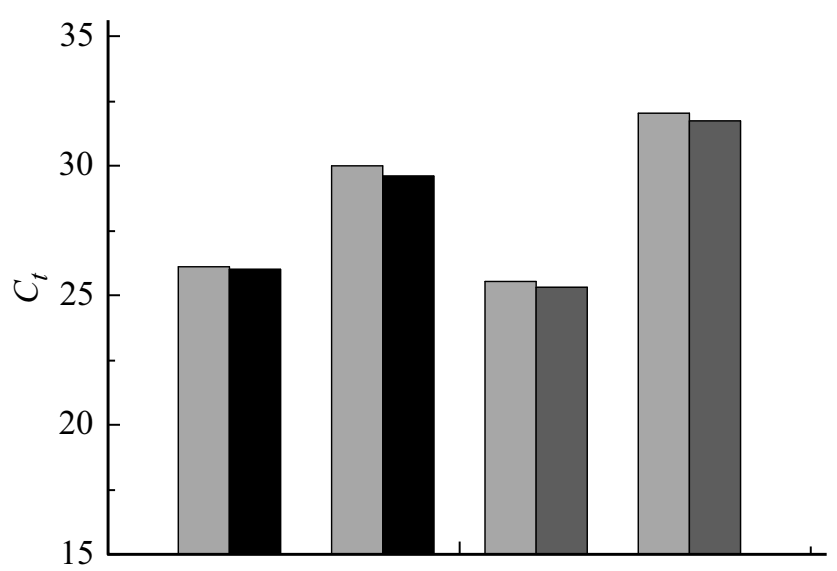

Рис. 1. Сравнение пороговых циклов ПЦР при исследовании влияния водорастворимых компонентов клея, появляющихся после нагрева жидкости в микрочипе (черный цвет) и при оценке адсорбции ДНК-мишени в случае хранения в микрочипе $2 \mathrm{~h}$ (темно-серый), с контрольными значениями (серый цвет) при исходной концентрациях ДНК 4000 и 200 копий на $\mu 1$.

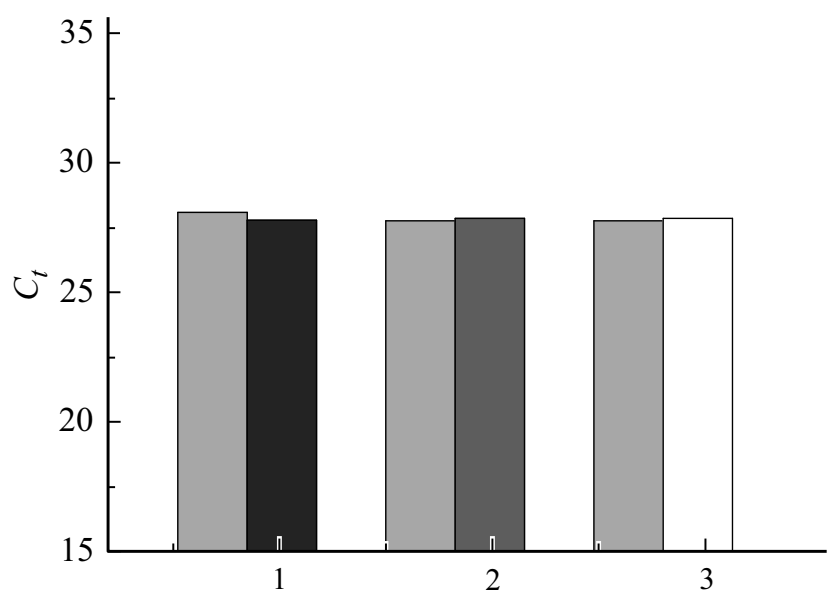

Рис. 2. Сравнение пороговых циклов ПЦР для исследования адсорбции в микрочипе Таq-полимеразы при временах хранения $24(1)$ и $2 \mathrm{~h}(2)$, а также при хранении в течение $2 \mathrm{~h}$ смеси без Таq-полимеразы (3) с контрольными значениями (серый цвет).

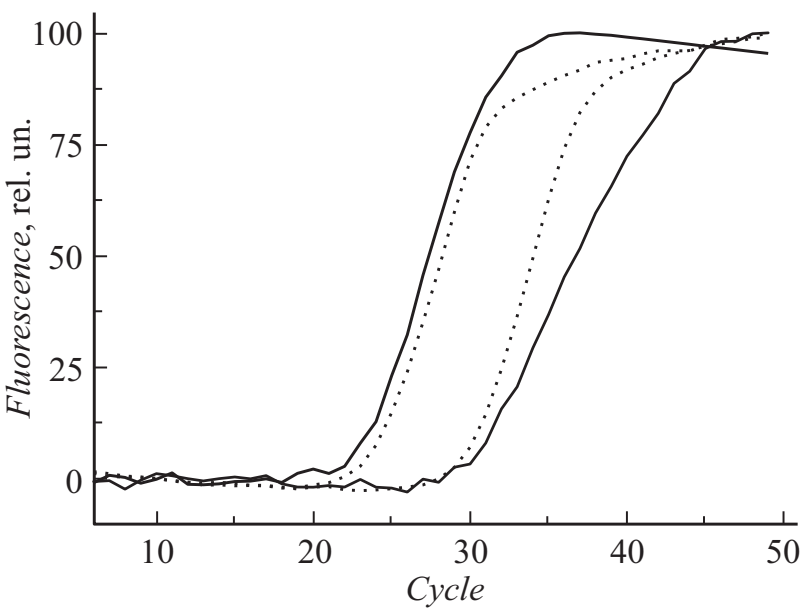

Рис. 3. Кинетические зависимости амплификации, полученные в микрочипе из ПММА (сплошная линия) и в полипропиленовых пробирках (пунктирная линия) при исходных концентрациях ДНК 4000 и 200 копий на $\mu 1$.

что, вероятно, обусловлено гидролизом поверхностного слоя материала. Дополнительно установлено, что из всех силиконовых компаундов только компонент „Б“ композиции Пентэласт-750 негативно влияет на скорость реакции (приводит к сдвигу порогового цикла ПЦР более чем на 1 цикл), тогда как в отвержденном состоянии силиконовый эластомер Пентэласт-750 уже не ингибирует ПЦР. Следовательно, все исследуемые материалы можно применять при изготовлении микроустройств для ПЦР, учитывая, что ПЭТГ и Пентэласт750 теряют прозрачность после нагрева в водной среде до температур $90-100^{\circ} \mathrm{C}$.

На рис. 1 представлены результаты ПЦР при замещении одного из компонентов реакции (воды, ДНКмишени) раствором из микрочипа. В первом случае в ходе термоциклирования в раствор могут переходить низкомолекулярные компоненты клея (обогащение раствора), во втором возможна адсорбция ДНК на стенках реакционной камеры (обеднение раствора). Однако разница пороговых циклов с контрольными пробирками не превышает 1.0 цикла при концентрациях ДНК 4000 копий на $\mu 1$ и 200 копий на $\mu 1$, поэтому можно предположить, что эти явления не вносят значимого вклада в результат реакции. Использование разных наборов реагентов для ПЦР обусловливает некоторые отличия в величине пороговых циклов между этими экспериментами.

На рис. 2 представлены результаты ПЦР при исследовании адсорбции SynTaq-полимеразы и остальных компонентов смеси в микрочипе при $+4^{\circ} \mathrm{C}$, которые сопоставимы с результатами аналогичного хранения в полипропиленовых пробирках (светло-серый цвет). Следовательно, при данных условиях значительной адсорбции полимеразы не наблюдается. 
При проведении ПЦР-РВ в микрочипах были получены сопоставимые с пробирками графики зависимостей флуоресценции от цикла ПЦР (рис. 3). При концентрации ДНК $\sim 200$ копий на $\mu 1$ в микрочипе наблюдается увеличение наклона зависимости с поздним выходом на плато, что может свидетельствовать об уменьшении эффективности реакции.

\section{5. Обсуждение результатов}

Полученные результаты подтверждают отсутствие ингибирования ПЦР для известных материалов (СОР, ПК, ПДМС), но в то же время не совпадают с результатами других исследователей [17] для ПММА и эпоксидных компаундов. Вероятно, это может быть связано с разной площадью поверхности образцов, а также использованием другой полимеразы (SynTaq). В работе [17] использовали скоростную SpeedStar-полимеразу, а материал разрезали ножницами на 10-100 кусков. В другой работе [10] полимерные капилляры нарезали $\mathrm{CO}_{2}$-лазером. Поскольку сложно одинаково измельчить разные по своей природе материалы, и велика вероятность их загрязнения в процессе дробления, в настоящей работе для предварительной оценки влияния материалов на результат ПЦР применялся подход на основе сопоставимой массы образцов материала. Также не следует исключать тот факт, что в отличие от аналогичных работ исследуются отечественные материалы и наборы реагентов, которые могут отличаться технологией производства и химическим составом от зарубежных аналогов.

Надо отметить, что и ПММА, ПК и ПДМС также поначалу были признаны не ингибирующими ПЦР [11]. Однако растет число статей, которые признают негативное влияние этих материалов на ПЦР при анализе малых концентраций ДНК-мишени $[5,9,18]$, что в основном связывают с адсорбцией компонентов на стенках микроструктур. Результаты, полученные нами при использовании растворов, хранившихся в микрочипах из ПММА при $+4^{\circ} \mathrm{C}$, свидетельствуют об отсутствии значимой адсорбции компонентов даже при уменьшении исходной концентрации ДНК-мишени. Однако наблюдаемое увеличение наклона зависимости в микрочипе при уменьшении концентрации ДНК (рис. 3) требует проведения дальнейших исследований. К одному из предполагаемых факторов, влияющих на результат анализа, относятся условия хранения реагентов в микрочипе. В данном случае по аналогии с работами $[7,17]$ для исследования адсорбции реагентов микрочипы хранили при температуре не выше комнатной. В дальнейшем планируется исследовать разные условия хранения, а также менять соотношение компонентов реакционной смеси, в том числе, добавляя БСА.

\section{Заключение}

Было установлено, что полиметилметакрилат марок TOCП, TOCH, ACRYMA 72, поликарбонат марки Novattro, эпоксидные клеи-компаунды ПЭО-210 и ПЭО-221, силиконовые эластомеры Пентэласт-712, Пентэласт-750, Силастик Т4, КРЕОЛ и СКТН отечественных производителей не ингибируют реакцию при добавлении образцов (3 $\mathrm{mg}$ ) в пробирки для ПЦР (см. табл. 1 и 2). В тех же условиях не ингибируют ПЦР полиуретан PR 700, медицинский поливинилхлорид, полиэтилентерефталат и полиэтилентерефталатгликоль зарубежных производителей, а также это подтверждено для полидиметилсилоксана Sylgard-184, циклоолефинов ZeoNex и Zeonor. Фотоотвержаемый клей на акрилатной основе Permabond UV 630, применяемый для склеивания микрочипов из ПММА, не оказывает негативного влияния на ПЦР. При непродолжительном хранении реагентов в микрочипе (при температуре не выше комнатной) адсорбция SynTaq-полимеразы и ДНК-мишени не наблюдается. Однако в микрочипе происходит снижение эффективности реакции при проведении ПЦР с исходной концентрацией ДНК 200 копий на $\mu$, для установления причины которой необходимы дальнейшие исследования.

\section{Конфликт интересов}

Авторы заявляют, что у них нет конфликта интересов.

\section{Список литературы}

[1] Hopwood A.J., Hurth C., Yang J., Cai Z., Moran N., LeeEdghill J.G., Nordquist A., Lenigk R., Estes M.D., Haley J.P., McAlister C.R., Chen X., Brooks C., Smith S., Elliott K., Koumi P., Zenhausern F., Tully G. // Analyt. Chem. 2010. Vol. 82. N 16. P. 6991-6999. DOI: 10.1021/ac101355r

[2] Qiu X., Chen D., Liu C., Mauk M.G., Kientz T., Bau H.H. // Biomed. Microdevices. 2011. Vol. 13. N 4. P. 809-817. DOI:10.1007/s10544-011-9551-5

[3] Stedtfeld R.D., Tourlousse D.M., Seyrig G., Stedtfeld T.M., Kronlein M., Price S., Ahmad F., Gulari E., Tiedje J.M., Hashsham S.A. // Lab Chip. 2012. Vol. 12. N 8. P. $1454-1462$. DOI: $10.1039 / \mathrm{c} 21 \mathrm{c} 21226 \mathrm{a}$

[4] Lee N.Y. // Microchim. Acta. 2018. Vol. 185. P. 285. DOI: $10.1007 / \mathrm{s} 00604-018-2791-9$

[5] Crabtree H.J., Lauzon J., Morrissey Y.C., Taylor B.J., Liang T., Johnstone R.W., Stickel A.J., Manage D.P., Atrazhev A., Backhouse C.J., Pilarski L.M. // Microfluid Nanofluid. 2012. Vol. 13. P. 383-398. DOI: $10.1007 / \mathrm{s} 10404-012-0968-9$

[6] Shoffner M.A., Cheng J., Hvichia G.E., Kricka L.J., Wilding P. // Nucl. Acid. Res. 1996. Vol. 24. P. 375-379. DOI: $10.1093 /$ nar/24.2.375

[7] Автореф. канд. дис. Лаврова М.В. Разработка микрофлюидной аналитической системы для экспрессного определения ДНК методом полимеразной цепной реакции в режиме реального времени: 02.00.02 СПб, 2007. С. 23. 
[8] Taylor T.B., Winn-Deen E.S., Picozza E., Woudenberg T.M., Albin M. // Nucl. Acid. Res. 1997. Vol. 25. N 15. P. 3164-3168. DOI: 10.1093/nar/25.15.3164

[9] Xia Y.-M., Hua Z.-S., Srivannavit O., Ozel A.B., Gulari E. // J. Chem. Technol. Biotechnol. 2007. Vol. 82. P. 33-38. DOI: $10.1002 / \mathrm{jctb} .1631$

[10] Phaneuf C.R., Oh K., Pak N., Saunders D.C., Conrardy C., Landers J.P., Tong S., Forest C.R. // Biomed Microdevices. 2013. Vol. 15. P. 221-231. DOI 10.1007/s10544-012-9720-1

[11] Zhang C., Xu J., Ma W., Zheng W. // Biotechnol. Adv. 2006. Vol. 24. N 3. P. 243-284.

DOI: $10.1016 /$ j.biotechadv.2005.10.002

[12] Лукашенко Т.А., Тупик А.Н., Рудницкая Г.Е., Буляница А.Л., Цымбалов А.И., Евстрапов А.А. // Научное приборостроение. 2016. Т. 26. Вып. 2. С. 64-74.

DOI: $10.18358 / \mathrm{np}-26-2-\mathrm{i} 6474$

[13] Тупик А.Н., Лукашенко Т.А. // Тезисы докладов III Междунар. науч.-техн. конф. „Современные достижения в области клеев и герметиков: материалы, сырье, технологи““ Н. Новгород, 2019. С. 231-233.

[14] Wan W., Yeow J.T.W. // Nanotechnology. 2009. Vol. 20. N 32. 325702. DOI: $10.1088 / 0957-4484 / 20 / 32 / 325702$

[15] Gao C.-H., Mortimer M., Zhang M., Holden P.A., Cai P., $W u$ S., Xin Y., Wu Y., Huang Q. // Peer J. 2019. Vol. 7. P. e7228. DOI: $10.7717 /$ peerj.7228

[16] Gonzalez A., Grimes R., Walsh E.J., Dalton T., Davies M. // Biomed Microdevices. 2007. Vol. 9. P. 261-266.

DOI: $10.1007 / \mathrm{s} 10544-006-9030-6$

[17] Kodziusa R., Xiaoc K., Wud J., Yid X., Gongd X., Fouldsb I.G., Wen W. // Sensors Actuat. B: Chem. 2012. Vol. 161. P. 349-358. DOI: 10.1016/j.snb.2011.10.044

[18] Hurth C., Yang J., Barrett M., Brooks C., Nordquist A., Smith S., Zenhausern F. // Biomed Microdevices. 2014. Vol. 16. N 6. P. 905-914.

DOI: $10.1007 / \mathrm{s} 10544-014-9895-8$ 